\title{
Superhydrophilic Microporous Silica Coatings on Polymer Substrate
}

\author{
Wataru SHIMIZU, Taki MATSUMOTO, Shohei HOSOO, Hitoshi NAGAHIRA and Yasushi MURAKAMI \\ Department of Fine Materials Engineering, Faculty of Textile Science and Technology, Shinshu University, Tokida, Ueda 386-8567
}

\begin{abstract}
A transparent smooth superhydrophilic silica coating has been developed by coating a polyethylene terephthalate (PET) substrate with microporous silica and immersing the microporous silica coating in water at $80^{\circ} \mathrm{C}$. The microporous precursor sol for coating was synthesized from tetramethoxysilane under neutral conditions by accelerating the rate of the condensation with hydroxyacetone. Immersing the coating in water is an important process for removing not only the methoxy group, but also the hydroxyacetone to form the hydrophilic surface.
\end{abstract}

[Received August 15, 2007; Accepted October 18, 2007]

Key-words : Superhydrophilic, Microporous silica, Tetramethoxysilane, Non-ionic catalyst, Anti-fog

\section{Introduction}

An anti-fog coating on a substrate, such as a glass or polymer, is used to keep car windows, bathroom mirrors, camera lenses, eyeglasses and greenhouses from fogging up. Fog is caused when steam condenses on a cool surface and then forms water droplets due to the surface tension of water. Water molecules are more attracted to each other than to air molecules and form a spherical shape. The anti-fog coating material is hydrophobic or superhydrophilic (contact angles of water droplets are less than $5^{\circ}$ ); the hydrophobic coating repels water to form drops of water which roll on the surface, while on the superhydrophilic coating, the water spreads out without becoming drops of water.

A $\mathrm{TiO}_{2}$ coating shows a remarkable antifogging effect. Both superhydrophilicity and superoleophilicity are induced on a $\mathrm{TiO}_{2}$ surface by ultraviolet (UV) irradiation. ${ }^{1)}$ The $\mathrm{TiO}_{2}$ coating first needs to be irradiated by UV light for the antifogging effect and does not work for long time in the dark.

Recently, Bico et al. quantitatively discussed the wetting of a solid textured by a designed roughness. ${ }^{2)}$ For a hydrophilic solid substrate, the liquid-solid contact is favored and the hydrophilicity is enhanced by the surface roughness. The liquid is in contact with a rough surface which consists of the solid and pores. Considering both air and liquid with which the pore is filled, the contact angle is described by the following equation,

$$
\begin{aligned}
\cos \theta^{*}= & \phi_{s} \cos \theta_{s}+\left(1-\phi_{s}\right) r_{a} \cos \theta_{a} \\
& +\left(1-\phi_{s}\right)\left(1-r_{a}\right) \cos \theta_{l}
\end{aligned}
$$

where $\theta^{*}$ is the apparent contact angle of the liquid on the rough surface, $\theta_{s}$ is the contact angle of the liquid on the smooth surface of the solid, $\phi_{s}$ is the fraction of the base of the liquid drop in contact with the solid, $\theta_{a}$ is the contact angle of the liquid on the air with which the pore is filled $\left(\theta_{a}=\pi\right), r_{a}$ is the fraction of the open cross-section of the pore filled with the air, and $\theta_{l}$ is the contact angle of the liquid on the liquid with which the pore is filled $\left(\theta_{l}=0\right)$. The contact angle can be described by the following equation.

$$
\cos \theta^{*}=\left(1-\phi_{s}\right)\left(1-2 r_{a}\right)+\phi_{s} \cos \theta_{s}
$$

For the porous material, the fraction of the base of the liquid drop in contact with the solid is small. The apparent contact angle of the liquid on the porous material surface decreases with a decrease in the fraction of the top of the pore filled with the air. During the measurement of the contact angle of water, the water is dropped onto the surface in order to fill the pore. $r_{a}$ in Eq. (2) is then almost zero as

$$
\cos \theta^{*}=1-\phi_{s}\left(1-\cos \theta_{s}\right)
$$

Practically, the entire volume of the pore was not necessarily filled with water under the normal conditions of temperature and humidity.

The volume fraction of the pore filled with water under normal conditions needs to be considered. The multifunctional nanoporous thin films, which exhibit both the superhydrophilic wetting characteristic and a low refractive index, have been fabricated. ${ }^{3)}$ The superhydrophilic porous material involves the pores filled with water, whereas the porous material with a low refractive index involves the pores filled with air.

The adsorption types of water depend on the pore sizes; i.e., the monolayer adsorption of water on the surface of micropores and multilayer adsorption of water on the surface of mesopores. If almost the entire surface of the porous material consists of the inner surface of micropores, only the monolayer adsorption of water occurs and the adsorption strength simply depends on the hydrogen bond strength between a water molecule and an oxygen atom at the inner surface of the micropores.

Hyrophilic coating solutions have been synthesized by adding glycidoxypropyltrimethoxysilane (GPS) to the colloidal silica suspensions adjusted to different $\mathrm{pHs}$, with which a PET substrate is coated. ${ }^{4)}$ The superhydrophilicity of the coating is developed by the preparation of a coating solution under highly acidic conditions ( $\mathrm{pH} 1$ or 2 ). The glycidoxypropyl group remains after the complete hydrolysis of the alkoxy group has occurred.

Microporous coating solutions have never been synthesized from a silicon alkoxide with an ionic catalyst. Under a slight degree of hydrolysis of tetramethoxysilane, the microporous powders are obtained in poor yield..$^{5)}$ Competitive reactions forming by-products will be accelerated by the ionic catalyst. An alternative catalyst is required for the preparation of the microporous precursor for coating.

In this study, we demonstrate that the apparently smooth and microporous surface can be readily created below $80^{\circ} \mathrm{C}$ not from silica nanoparticles or silicon alkylalkoxide, but from silicon alkoxide such as tetramethoxysilane with hydroxyacetone as the non-ionic catalyst under neutral conditions. The superhydrophilic coating on a PET substrate prevents light scattering water droplets from forming on the surface. The antifogging mechanism will be clarified by changing the immersing condition.

\section{Experimental}

The solution used for the microporus silica coating is syn- 
thesized from a mixture of tetramethoxysilane $\left(\mathrm{Si}\left(\mathrm{OCH}_{3}\right)_{4}\right.$, Kanto >98\%), water, hydroxyacetone $\left(\mathrm{CH}_{3} \mathrm{COCH}_{2} \mathrm{OH}\right.$, Kanto $>80 \%$ ) as the catalyst, and methanol (Wako $>99.5$ $\%)$ as the solvent. The molar ratio of $\mathrm{Si}\left(\mathrm{OCH}_{3}\right)_{4}: \mathrm{H}_{2} \mathrm{O}$ : $\mathrm{CH}_{3} \mathrm{COCH}_{2} \mathrm{OH}$ is $1: 1: 5$. Water is deionized by an AQUARIUS GS-200 System (Advantec), while the other reagents are used without further purification. The mixture is stirred at $25^{\circ} \mathrm{C}$ for 24 hours and then aged at $40^{\circ} \mathrm{C}$ for four days. 2-Ethoxyethanol (Wako $>98 \%$ ) is added to the solution, and methanol is removed by evaporation in order to smooth the surface of the coating film. The coating solution is dropped onto a PET (SANPLATEC), nonluminescent quartz plate (Tosoh) or mirror polished silicon wafer (Komatsu Electronics $>99.9999 \%$ ) and spun at $1000 \mathrm{rpm}$ for $60 \mathrm{~s}$ at $25^{\circ} \mathrm{C}$. The coating on the substrate is dried at $25^{\circ} \mathrm{C}$ or $80^{\circ} \mathrm{C}$ for two hours, immersed in water at $80^{\circ} \mathrm{C}$ for two hours and then dried at $25^{\circ} \mathrm{C}$.

The pore structure of the coating is determined by the nitrogen gas adsorption/desorption technique (Micromeritics ASAP2020) for the bulk gel prepared from identical silicate precursors. The thickness of the coatings is measured using a surface profilometer (ULVAC Dektak 6M). The pencil hardness of the coating on a silicon wafer is measured by a Japanese Industrial Standard method (JIS-K-5400). The optical transmission spectra of the coating on a quartz glass are obtained using an UV-visible spectrometer (Shimadzu UV-2100) in the wavelength range of $300-800 \mathrm{~nm}$. The surface morphology of the coating on a silicon wafer was observed using an atomic force microscope (AFM, Seiko Instruments SPA400). The surface wettability of the coating on a silicon wafer was evaluated from the contact angle measurement at room temperature using a contact angle meter (Kyowa Interface Science DropMaster 300). The averaged contact angle was calculated from five measured values at different points of the coating. The Fourier transform infrared (FT-IR) spectra of the coating were measured with an FT-IR spectrometer (Shimadzu IRPrestige-21), which was attached to an attenuated total reflection (ATR) unit equipped with a monolithic diamond prism crystal, in the range of $700-4000 \mathrm{~cm}^{-1}$.

\section{Results}

The superhydrophilicity was developed by coating a PET substrate with microporous silica and immersing the microporous silica coating in water at $80^{\circ} \mathrm{C}$ as compared to hydrophobicity of a bare PET substrate. Figure 1 shows that a water droplet spread out on the superhydrophilic silica-coated PET, while a semispherical droplet of water remained on the hydrophobic bare PET.

The superhydrophilic coating of silica was highly transparent as shown in the inset of Fig. 2. Transparent quartz was used as a substrate instead of the PET since the surface of the PET substrate is rough. Figure 2 shows the optical transmission spectra of the coating on a transparent substrate of quartz in the wavelength range of $300-800 \mathrm{~nm}$. The transmittance of the silica coating reached approximately $100 \%$ of incidence in the visible region.

The superhydrophilic coating was smooth in the presence of micropores. Figure 3 (a) shows an AFM topographical image of the coating on a highly smooth silicon substrate. A smooth silicon substrate was used instead of the PET substrate since the surface of the PET substrate is rough. A typical crosssectional profile (Fig. 3(b)) indicates a vertical interval within $3 \mathrm{~nm}$. The roughness was only three percent of the thickness of the coating $(100 \mathrm{~nm})$. The roughness due to a

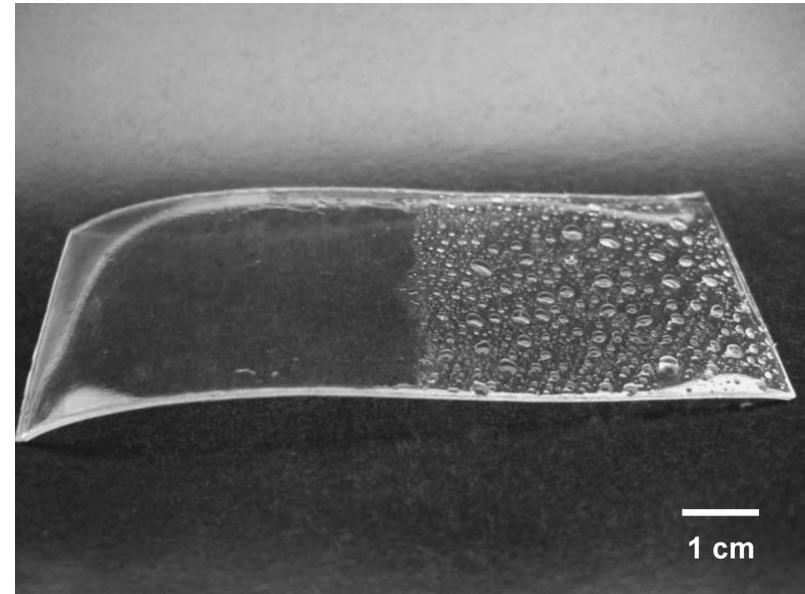

Fig. 1. A superhydrophilic coating on a PET substrate on the left half and a hydrophobic bare PET substrate on the right half. After coating half of the substrate with microporous silica, the coatings are immersed in water at $80^{\circ} \mathrm{C}$ for two hours that causes hydrolysis of the remaining alkoxy groups. Water is sprayed after drying the half-coated substrate at $25^{\circ} \mathrm{C}$ for one day.

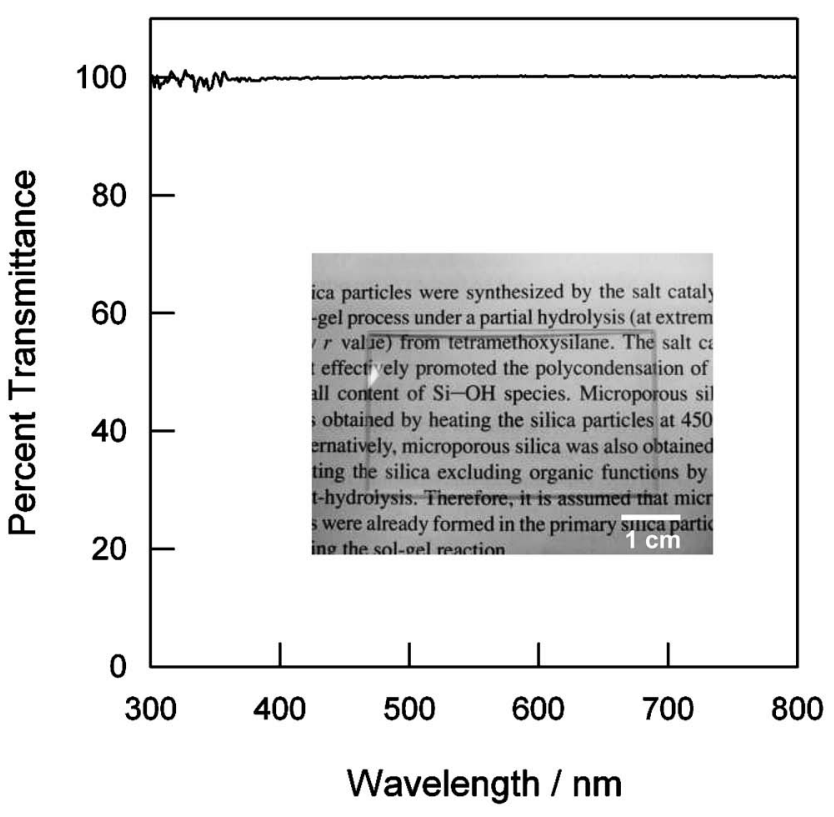

Fig. 2. Optical transmission spectra of a superhydrophilic coating on a quartz substrate. The inset is a photograph of the superhydrophilic coatings on a quartz substrate.

micropore in the coating is visually imperceptible.

The specific surface areas of dried bulk gel, which was prepared from coating sol, are shown in Table 1. Immersing silica in water at $80^{\circ} \mathrm{C}$ increased the specific surface area of the silica $\left(700 \mathrm{~m}^{2} \mathrm{~g}^{-1}\right)$ compared to that of the as-prepared one $\left(410 \mathrm{~m}^{2}\right.$ $\left.\mathrm{g}^{-1}\right)$. The increase in the specific surface area was caused by the pore distribution change. Figure 4 shows the nitrogen adsorption-desorption isotherms for the as-prepared silica and two kinds of silica immersed in water. The isotherm is I type for all of the silica, which indicates that the high specific surface area of the silica is due to the microporous structure. ${ }^{6}$ The pore size for the as-prepared silica has a narrow distribution and a mode diameter of the pore is less than $0.8 \mathrm{~nm}$. 


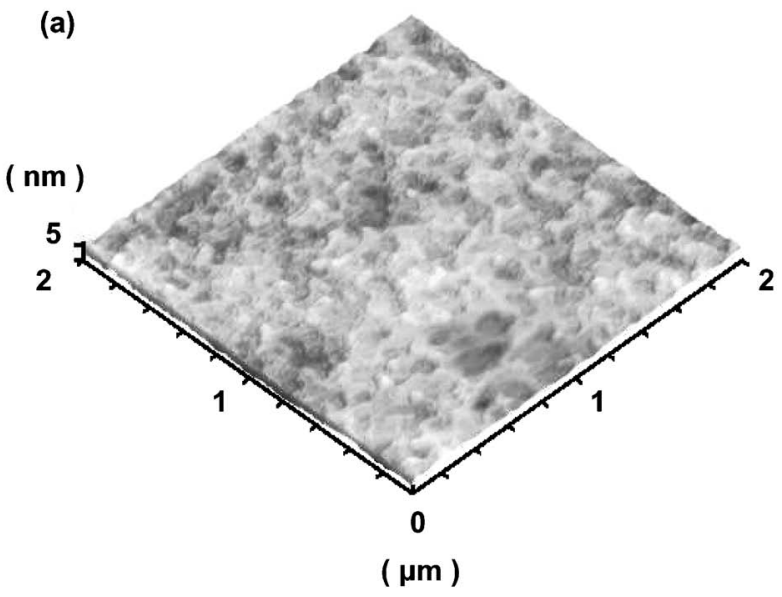

(b)

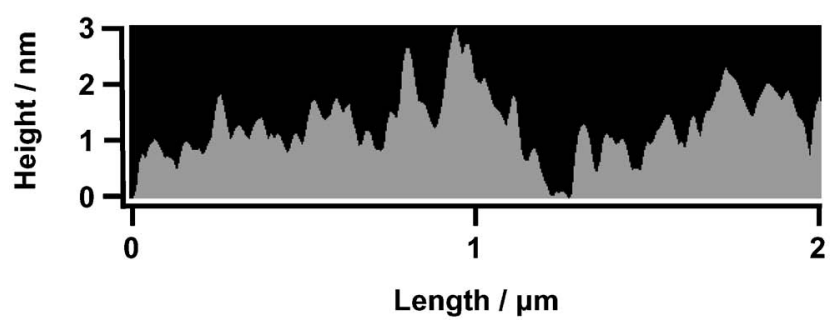

Fig. 3. (a) An AFM topographical image of a superhydrophilic coating on a silicon substrate. (b) A typical cross-sectional profile. The thickness of the coatings is estimated to be $100 \pm 2 \mathrm{~nm}$.

Table 1. Immersion Effects on the Silica Coating

\begin{tabular}{ccccc}
\hline $\begin{array}{c}\text { Immersing } \\
\text { temperature }\end{array}$ & $\begin{array}{c}\text { Film } \\
\text { thickness } \\
/ \mathrm{nm}\end{array}$ & $\begin{array}{c}\text { Specific } \\
\text { surface area } \\
/ \mathrm{m}^{2} \mathrm{~g}^{-1}\end{array}$ & $\begin{array}{c}\text { Pencil } \\
\text { hardness }\end{array}$ & $\begin{array}{c}\text { Contact } \\
\text { angle }\end{array}$ \\
\hline $80^{\circ} \mathrm{C}$ & 100 & 700 & $2 \mathrm{H}$ & $3.4^{\circ}$ \\
$25^{\circ} \mathrm{C}$ & 100 & 510 & $2 \mathrm{H}$ & $11.6^{\circ}$ \\
as-prepared & 105 & 410 & $2 \mathrm{~B}$ & $29.5^{\circ}$ \\
\hline
\end{tabular}

Immersing a microporous silica in water at $80^{\circ} \mathrm{C}$ expanded the mode diameter of the pore to $0.8 \mathrm{~nm}$.

Hydrolysis of the remaining alkoxy groups proceeded by immersing the silica coating in water at $80^{\circ} \mathrm{C}$. Figures 5 and 6 show the infrared spectra of the as-prepared coating and two kinds of coatings immersed in water at $25^{\circ} \mathrm{C}$ and $80^{\circ} \mathrm{C}$. Immersing the silica coating in water increased the absorptions at a broad band centered near $3400 \mathrm{~cm}^{-1}$, a small band at 1630 $\mathrm{cm}^{-1}$ and a sharp band at $950 \mathrm{~cm}^{-1}$ (Fig. 5). The broad band centered near $3400 \mathrm{~cm}^{-1}$ is assigned to the hydrogen bonded SiO-H stretching vibrations $\left(3200-3650 \mathrm{~cm}^{-1}\right)$, hydrogen bonded water $\left(3300-3500 \mathrm{~cm}^{-1}\right)$ and hydrogen bonded $\mathrm{OH}$ vibrations of alcohols $\left(3300-3600 \mathrm{~cm}^{-1}\right)$ which are possibly of methanol, 2-ethoxyethanol and hydroxyaceton in the case of this study. ${ }^{6)-8)}$ The small band at $1630 \mathrm{~cm}^{-1}$ is assigned to the scissor bending vibration of the adsorbed molecular water, while the band at $950 \mathrm{~cm}^{-1}$ is assigned to the Si-OH stretching of the terminal silanol groups. ${ }^{7)-9)}$ An isolated SiO-H stretching vibrations, which occurs at $3650-3800 \mathrm{~cm}^{-1},{ }^{7)}$ is not detected in these spectra. This result indicates that most of the silanol groups in these silica coatings are hydrogen bonded to water. The distinguishing band of hydroxyacetone, which is

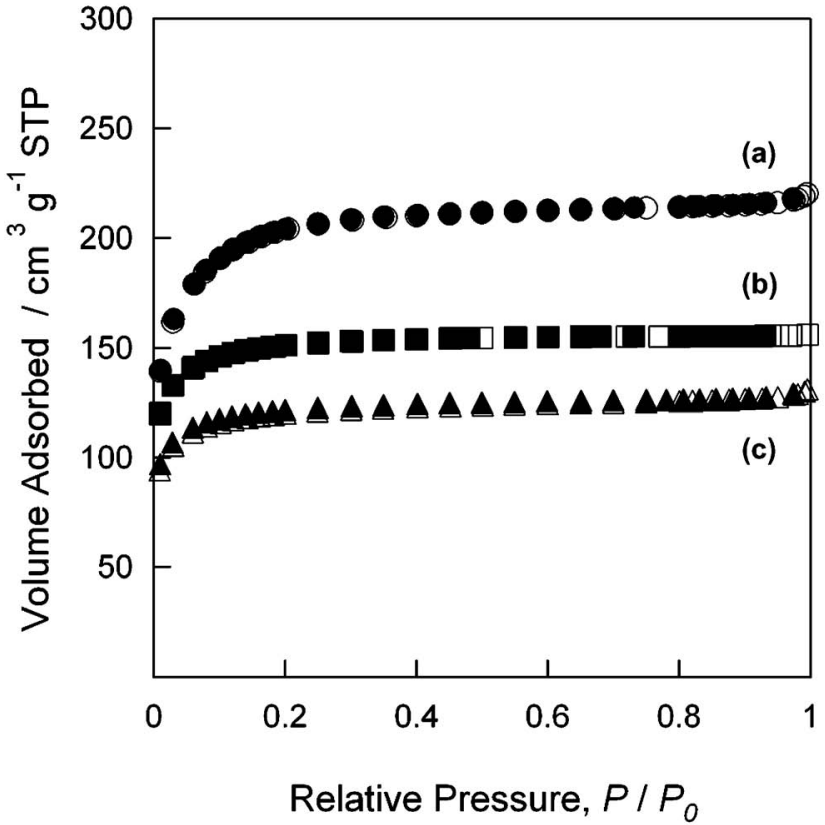

Fig. 4. Nitrogen adsorption (open)/desorption (solid) isotherms of the silica powders (a) immersed in water at $80^{\circ} \mathrm{C}$ for two hours, (b) immersed in water at $25^{\circ} \mathrm{C}$ for two hours, and (c) as-prepared.

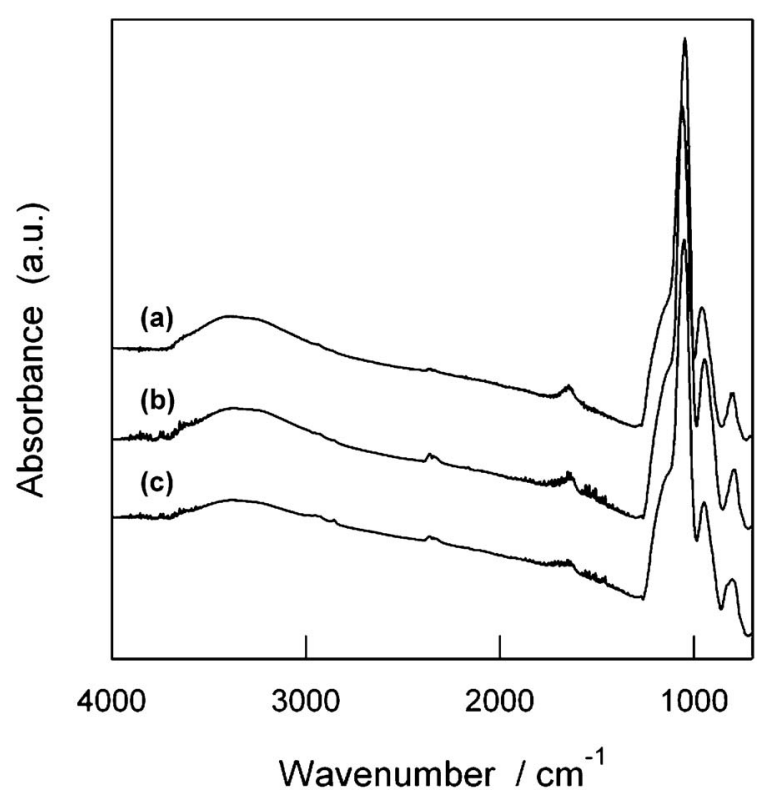

Fig. 5. FT-IR spectra at $700-4000 \mathrm{~cm}^{-1}$ of the silica coatings on a silicon substrate (a) immersed in water at $80^{\circ} \mathrm{C}$ for two hours, (b) immersed in water at $25^{\circ} \mathrm{C}$ for two hours, and (c) as-prepared.

observed at $1715 \mathrm{~cm}^{-1}$, was not detected in all of the spectra. On the other hand, immersing the silica coating in water decreased the absorptions bands at 2950 and $2850 \mathrm{~cm}^{-1}$ (Fig. 6). These bands are assigned to the $\mathrm{C}-\mathrm{H}$ stretching of the alkoxy groups. ${ }^{10), 11)}$ The alkoxy groups remained in the as-prepared coating. The reaction system for the preparation of the microporous silica involved only a molecule of water per tetramethoxysilane molecule to leave the alkoxy groups after hydrolysis and condensation. The hydroxyl group increased whereas the alkoxy group decreased. Hydrolysis of 


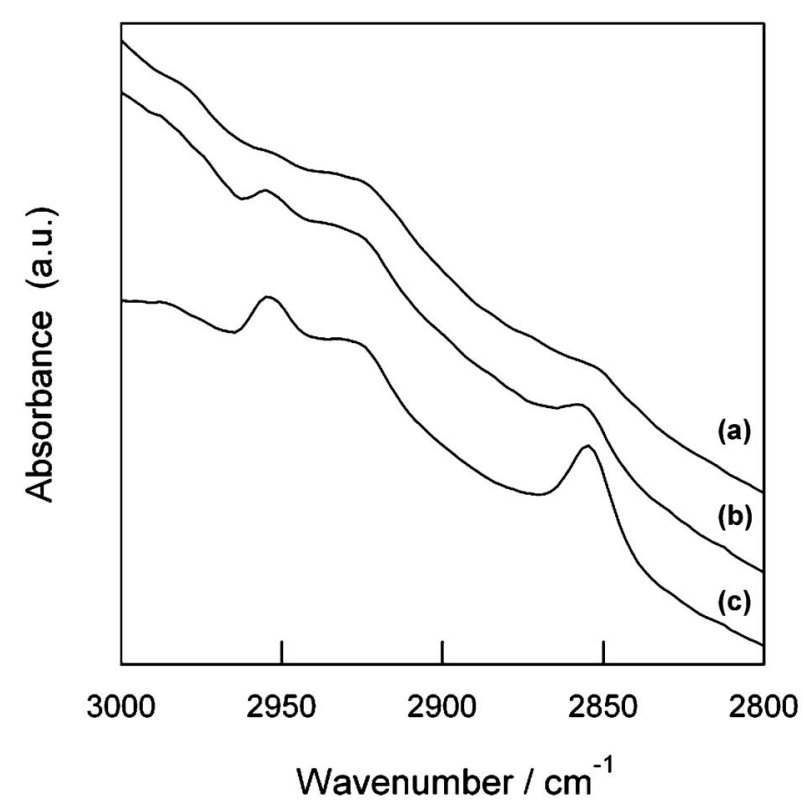

Fig. 6. FT-IR spectra at $2800-3000 \mathrm{~cm}^{-1}$ of the silica coatings on a silicon substrate (a) immersed in water at $80^{\circ} \mathrm{C}$ for two hours, (b) immersed in water at $25^{\circ} \mathrm{C}$ for two hours, and (c) as-prepared.

the remaining alkoxy groups to hydroxyl groups proceeded by immersing the silica coating in water. Absorption bands, which consist of a shoulder at $1220 \mathrm{~cm}^{-1}$ and distinct peak at $1080 \mathrm{~cm}^{-1}$, are slightly increased by immersing the silica coating in water. These bands are assigned to the longitudinal optical (LO) mode and the transverse optical (TO) mode of the asymmetric $\mathrm{Si}-\mathrm{O}$ stretching vibration, respectively, ${ }^{7,8)}$ whereas the band at $800 \mathrm{~cm}^{-1}$, the intensity of which almost did not change when immersing in the water, is assigned to the symmetric Si-O-Si stretching or vibrational modes of the ring structure. ${ }^{12), 13)}$ The change in the Si-O bonds is not recognizable due to the small rate of change in the initial quantity.

Immersing microporous silica in water at $80^{\circ} \mathrm{C}$ facilitated the adsorption of water on the micropores of the silica. Based on the thermogravimetry, for the silica immersed in water at $80^{\circ} \mathrm{C}$, the mass decrease developed in two stages (Fig. 7 (a)): rapid elimination of the adsorbed water below $120^{\circ} \mathrm{C}$ and gradual elimination of hydroxyl groups through dehydrating condensation over a wide range of temperatures. The amount of adsorbed water on the silica immersed in water at $80^{\circ} \mathrm{C}$ is almost four times greater than that on the as-prepared silica. The hydrolysis of the remaining methoxy groups to hydroxy groups facilitated the adsorption of water on the micropores of the silica. The behavior of the mass decrease of the silica immersed in water at $25^{\circ} \mathrm{C}$ was similar to that at $80^{\circ} \mathrm{C}$ (Fig. 7 (b)). The amount of water adsorbed on the silica immersed in water at $25^{\circ} \mathrm{C}$ is lower than that at $80^{\circ} \mathrm{C}$, which depended on a decrease in the surface area or the pore volume. Methoxy groups slightly remained after immersing the silica in water at $25^{\circ} \mathrm{C}$, while they were completely removed during the immersion at $80^{\circ} \mathrm{C}$. The elimination process of the as-prepared silica was more complicated (Fig. 7 (c)). Organic functional groups, such as methoxy groups, and high boiling point organic compounds, such as hydroxyacetone and 2-ethoxyethanol, remained in the as-prepared silica. The mass decreases were observed to occur in two steps: the decrease at $120-200^{\circ} \mathrm{C}$ was attributed to the combustion of hydroxyacetone and 2-ethoxyethanol and the decrease at $200-300^{\circ} \mathrm{C}$ was

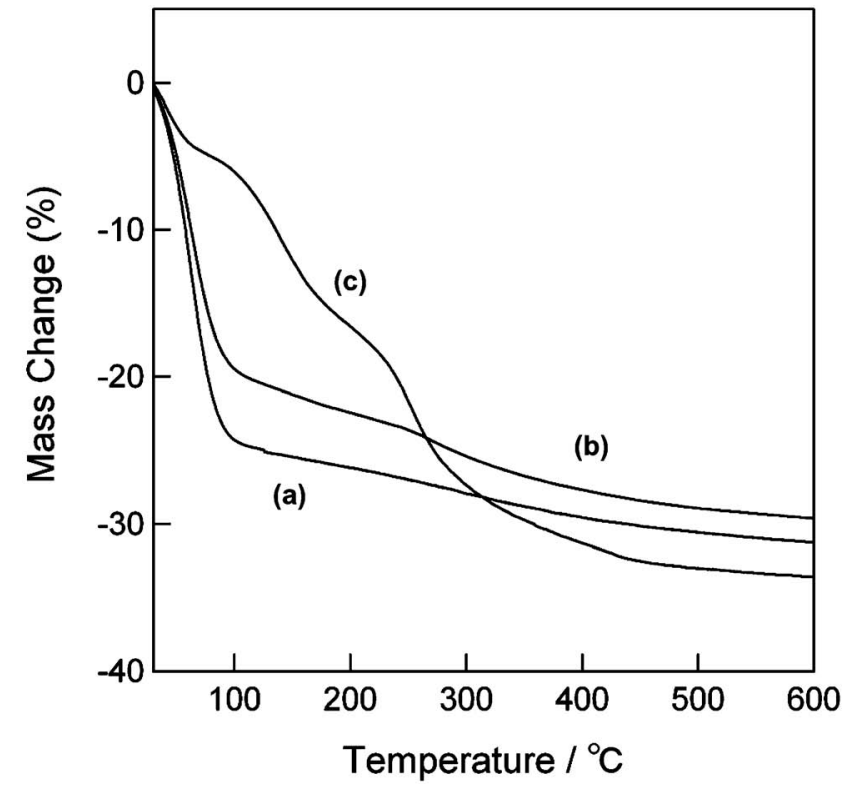

Fig. 7. Themo-gravimetry of the silicas (a) immersed in water at $80^{\circ} \mathrm{C}$ for two hours, (b) immersed in water at $25^{\circ} \mathrm{C}$ for two hours, and (c) as-prepared.
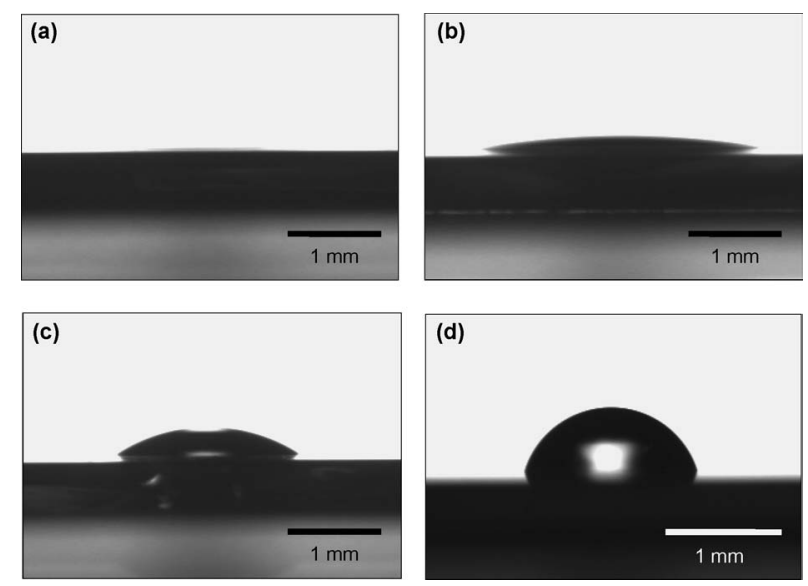

Fig. 8. Water drops onto the silica coatings on a silicon substrate (a) immersed in water at $80^{\circ} \mathrm{C}$ for two hours, (b) immersed in water at $25^{\circ} \mathrm{C}$ for two hours, and (c) as-prepared. (d) Semispherical drop of water on a bare silicon substrate.

attributed to the combustion of the methoxy groups.

Immersing a silica coating in water increased the hardness of the coating. The pencil hardness of the coating immersed in water was $2 \mathrm{H}$, while that of the as-prepared coating was $2 \mathrm{~B}$ (Table 1). By immersing the silica coating in water, a silica network will develop by hydrolysis of the remaining alkoxy groups and subsequent condensation of the generated hydroxy groups. The hardnesses of the coatings were quite different between the as-prepared silica coating and the coating immersed in water, although the thicknesses of all the coatings were about $100 \mathrm{~nm}$.

The superhydrophilicity was developed by immersion in water at $80^{\circ} \mathrm{C}$. The water contact angles, which were observed with a silica coating on a silicon substrate, are shown in Table 1. A drop of water immediately spreads over the coating immersed in water at $80^{\circ} \mathrm{C}($ Fig. $8($ a $)$ ), on which contact 
angle was $3^{\circ}$. The contact angle on the coating immersed in water at $25^{\circ} \mathrm{C}$ was $10^{\circ}$ (Fig. 8 (b)), while the contact angle on the as-prepared coating was $29^{\circ}$ (Fig. 8 (c)). The hydrophilicity depended on the extent of the hydrolysis of the methoxy groups. In contrast, the contact angle on a bare silicon substrate was $70^{\circ}$ (Fig. $8(\mathrm{~d})$ ).

\section{Discussion}

The superhydrophilic silica coating was prepared below $80^{\circ} \mathrm{C}$ and thereby applied to the coating on a polymer substrate such as a PET (Fig. 1). The micropores of the silica coatings are filled with water due to the adsorption of water. The presence of the infrared absorption band attributed to the hydrogen bonded $\mathrm{O}-\mathrm{H}$ vibrations and the mass decrease attributed to water elimination suggested water adsorption on the surface $\mathrm{OH}$ groups. The water drop is in contact with a rough surface which consists of the solid and the adsorbed water with which the micropore is filled.

The contact angle of water on the coating immersed in water at $25^{\circ} \mathrm{C}$, which has the remaining methoxy group, was $10^{\circ}$. The presence of the infrared absorption band attributed to the $\mathrm{C}-\mathrm{H}$ vibrations suggested residual methoxy groups. The remaining methoxy group would decrease the adsorption of water. The TG data suggested that the amount of water adsorbed on the silica immersed in water at $25^{\circ} \mathrm{C}$ is lower than that at $80^{\circ} \mathrm{C}$.

Hydroxyacetone as a non-ionic catalyst allows the preparation of the microporous silica precursor from tetramethoxysilane under neutral condition. As before, the microporous silica precursor has been hardly obtained and then the porosity is controlled by slowing the rate of evaporation as compared to the rate of condensation. In fact, the microporous bulk gel is readily obtained by the slow drying. ${ }^{6), 14)}$ On the other hand, we controlled the porosity by accelerating the rate of the catalytic hydrolysis with hydroxyacetone.

The pore size distribution was narrow and most of the pores are smaller than $1.5 \mathrm{~nm}$ in diameter. The pore size was so small that an apparently smooth surface was obtained.

Immersing the silica coating in water is an important process for removing not only the methoxy group, but also hydroxyacetone as a non-ionic catalyst. Accessibility to the back of the coating depended on the immersion temperature. The hardness of the coating immersed in water at $25^{\circ} \mathrm{C}$ is the same as that at $80^{\circ} \mathrm{C}$. Therefore, hydrolysis of the methoxy groups and the subsequent condensation of the hydroxyl groups would have already occurred at the surface layer of the coating. An increase in hardness of the silica coating immersed in water was also reported by Matsuda et al. ${ }^{15)}$

\section{Conclusion}

A transparent smooth superhydrophilic microporous silica coating on a PET substrate was developed by the hydrolysis of the remaining methoxy groups to hydroxy groups and the adsorption of water on the inner surface of the micropores at $80^{\circ} \mathrm{C}$. After the drying of the adsorbed water, the superhydrophilicity can be restored by the adsorption of water at a normal humidity and room temperature.

A microporous silica coating can be prepared from the microporous precursor sol, which was prepared from the simple silicon alkoxide under neutral conditions by accelerating the rate of the condensation with hydroxyacetone. Immersing the coating in water is an important process for removing not only the methoxy group, but also the hydroxyacetone.

Acknowledgements This work was supported by the Nagano Knowledge Cluster Initiative from the Ministry of Education, Culture, Sports, Science and Technology (MEXT).

\section{References}

1) R. Wang, K. Hashimoto, A. Fujishima, M. Chikuni, E. Kojima, A. Kitamura, M. Shimohigoshi and T. Watanabe, Nature, 388, 431-432 (1997).

2) J. Bico, U. Thiele and D. Quéré, Colloids Surf. A, 206, 41-46 (2002).

3) F. C. Cebesi, Z. Wu, L. Zhai, R. E. Cohen and M. F. Rubner, Langmuir, 22, 2856-2862 (2006).

4) K.-C. Song, J.-K. Park, H.-U. Kang and S.-H. Kim, J. Sol-Gel Sci. Tech., 27, 53-59 (2003).

5) Y. Murakami, K. Tanaka, Y. Takechi, S. Takahashi, Y. Nakano, T. Matsumoto, W. Sugimoto and Y. Takasu, $J$. Sol-Gel Sci. Tech., 29, 19-24 (2004).

6) C. J. Brinker and G. W. Scherer, "Sol-Gel Science," Academic Press, New York (1990) pp. 818-823.

7) P. Innocenzi, J. Non-Cryst Solids, 316, 309-319 (2003).

8) A. Zecchina, S. Bordiga, G. Spoto, L. Marchese, G. Petrini, G. Leofanti and M. Padovan, J. Phys. Chem., 96, 4991-4997 (1992).

9) R. M. Almeida and C. G. Pantano, J. Appl. Phys., 68, 4225-4232 (1990).

10) D. L. Ou and A. B. Seddon, J. Non-Cryst. Solids, 210, 187-203 (1997).

11) J. Méndez-Vivar and A. Mendoza-Bandala, J. Non-Cryst. Solids, 261, 127-136 (2000).

12) C. J. Brinker and G. W. Scherer, "Sol-Gel Science," Academic Press, NewYork (1990) pp. 541-546.

13) M. Nocuń and M. Handke, J. Mol. Struct., 596, 139-143 (2001).

14) G. C. Frye, A. J. Ricco, S. J. Martin and C. J. Brinker, "Better Ceramics Through Chemistry III,” Ed. by C. J. Brinker, D. E. Clark and D. R. Ulrich, Mat. Res. Soc., Pittsburgh, Pa. (1988) pp. 349-354.

15) A. Matsuda, T. Matoda, T. Kogure, K. Tadanaga, T. Minami and M. Tatsumisago, J. Sol-Gel Sci. Tech., 27, 61-69 (2003). 